\title{
Immunity to functional fixedness in young children
}

\author{
TIM P. GERMAN and MARGARET ANNE DEFEYTER \\ University of Essex, Colchester, England
}

\begin{abstract}
In the candle problem (Duncker, 1945), subjects must attach a candle to a vertical surface, using only a box of tacks and a book of matches. Subjects exhibit functional fixedness by failing, or being slow, to make use of one object (the tack box) as a support, rather than as a container, in their solutions. This failure to produce alternate functions is measured against improved performance when the tack box is presented empty rather than full of tacks (i.e., not preutilized as a container). Using an analogous task, we show that functional fixedness can be demonstrated in older children (6-and 7-year-olds); they are significantly slower to use a box as a support when its containment function has been demonstrated than when it has not. However, younger children (5-year-olds) are immune to this effect, showing no advantage when the standard function is not demonstrated. Moreover, their performance under conditions of preutilization is better than that of both older groups. These results are interpreted in terms of children's developing intuitions about function and the effects of past experience on problem solving.
\end{abstract}

In one of the classic problem-solving tasks of early experimental psychology, Duncker (1945) demonstrated functional fixedness, where subjects are hindered in reaching the solution to a problem by their knowledge of an object's conventional function. The original task required subjects to fix a candle onto a vertical surface so that it would be able to burn (the subjects had available candles, a book of matches, and a box of tacks and were encouraged to come up with multiple solutions). Duncker showed that the subjects were both less likely and slower to use the box as a platform for the candle (the preferred solution) than were subjects presented with the tacks and box separately (i.e., without pretutilization of the box for containment). Duncker suggested that the subjects were fixed on the conventional function of the box (containment) and hence were unable to reach the solution involving an alternative function (as a platform to support the candle). This initial result has been shown to be robust (Adamson, 1952), and functional fixedness has also been demonstrated in other object-use insight problems (see, e.g., Dominowski \& Dallob, 1995, for a review). ${ }^{1}$

Insight problems in general have been approached in information-processing frameworks (e.g., Ohlsson, 1984), and within this approach, object-use problems have received specific attention (Keane, 1989). Two key ideas are worth drawing out here. First, impasses in problem solving are thought to occur because operators relevant to the

This work was presented at the Biennial Meeting of the Society for Research in Child Development, Albuquerque. NM, April 1999. We thank Bernadette West and the rest of the staff, the children, and their parents at Broomgrove Primary School, Colchester. Thanks also to Steve Avons, Rick Hanley, Janet Metcalfe, Max Roberts, Steven Smith, Cristina Sorrentino, one anonymous reviewer, and especially Geoff Ward for helpful discussion of the issues raised here and/or comments on a previous version of this manuscript. Correspondence concerning this article should be addressed to T. P. German, Department of Psychology, University of Essex, Wivenhoe Park, Colchester, CO4 3SQ, England (e-mail: tgerm@essex.ac.uk). solution are not retrieved; as Keane puts it, "one fails to get access to the right plans in long-term memory" (p. 204). In the candle problem, for example, subjects might search for an element to act as a platform, but not consider the tack box for this purpose because there is a mismatch between the properties relevant for containment (e.g., opens and shuts) and those for support (e.g., is flat, is sturdy).

Second, it is supposed that impasses might be broken through restructuring (or re-encoding) of the problem. To illustrate this idea, Ohlsson (1984) describes how subjects in the two-cord problem (Maier, 1970), in which an object (e.g., a hammer) must be used as a pendulum weight in order to swing one cord over to the other, must re-encode their initial representation of the hammer. This is supposed to happen through spreading activation through semantic memory, involving abstraction from "hammer" through "tool" to "artifact" and then elaboration from "artifact" through "clock" to "pendulum." In insight problems, therefore, initial encoding of the problem and subsequent changes in this representation are assumed to be key elements in reaching a solution.

\section{COGNITIVE DEVELOPMENT AND PROBLEM SOLVING}

Increases in age and experience are generally thought to be associated with improvement in problem-solving ability. The intuition that children move from knowing less and solving problems poorly to knowing more and performing better has been characterized in different ways-for example, as a progression through qualitatively different stages of conceptual competence (e.g., Piaget, 1954), as access to increasingly efficient informationprocessing strategies (e.g., Case, 1985; Siegler, 1996), and more recently, as the acquisition of progressively more sophisticated commonsense theories about specific domains of knowledge, perhaps involving processes akin to "scientific" discovery (Gopnik \& Meltzoff, 1997). 
Numerous problem-solving tasks show that older children outperform younger children. A glance through a recent issue of any journal of developmental psychology will reveal papers showing age-related improvements in a host of psychological capacities. Indeed, the intuition that performance improves with age is so ingrained that chronological age and measures associated with general ability, such as verbal and nonverbal mental age, are often removed from regression analysis when attempting to establish relationships between cognitive abilities in development (see, e.g., Hughes, 1998, for a recent example assessing the relationship between executive function and theory of mind). Moreover, patterns of development that do not conform to this picture provoke controversy and intensive research (e.g., face perception in infancy: Morton \& Johnson, 1991; acquisition of past tense inflection: Marcus, Pinker, Ullman, Rosen, \& Xu, 1992).

Taken together then, there is an impressive array of intuition, theory, and evidence to suggest that with only a few exceptions, young children will perform poorly on a given problem-solving task when compared with older children. As far as Duncker's (1945) object use task is concerned, specific reasons to expect poor performance among young children can also be identified. In order to use the object in the way required by the problem, children must be creative in generating a novel alternative function for the object. One difficulty inherent in this is that children must set aside a current state of the world (i.e., the current and conventional function of the box). Inhibiting current salient information is known to be of extreme difficulty for younger children. Tasks assessing this aspect of executive function are performed extremely poorly by young children (see, e.g., Hughes, 1998; Russell, Jarrold, \& Potel, 1994). Indeed, Leslie and Polizzi (1998) have recently suggested that inefficient inhibitory processes might be the principal problem for younger children on the well-known and much investigated false belief task (Wimmer \& Perner, 1983).

Cumulatively, this evidence suggests that Duncker's (1945) functional fixedness problem will be no exception to the general rule that children's performance increases with age. In fact, given documented poor performance by younger children on tasks involving suppression of current information, functional fixedness might even be more marked at younger ages. However, recent research investigating the nature of children's developing conception of function suggests that children might not be susceptible to functional fixedness. German and Johnson (1996, 1997) and Kelemen (1999) have independently found evidence that young children's intuitions about function may be subtly different from those of adults. This evidence comes from tasks in which children are confronted with pictures of novel objects that are described as having been made for one purpose but now used to fulfill another. For example, children are shown a line drawing of an object that is said to have been made for trapping bugs but now is used to collect raindrops.
Whereas adults judge the originally intended function (trapping bugs) as the true function most of the time, 4and 5-year-old children are more likely than are adults to pick the novel function (collecting raindrops). Kelemen showed that 4-year-olds select the original function significantly more often than chance $(61 \%)$ but appear to do so less than adults (who did so $86 \%$ of the time). German and Johnson find that 5 -year-old children select the novel function and the original function equally often. In both cases, these results are set against judgments on stories in which the alternative activity happens by accident - in these control stories, children choose the original function.

These results are consistent with the hypothesis that younger children have wider criteria for what can count as an object's function than do adults (German \& Johnson, 1997). Rather than taking into account only the proper function of an object, they adopt an agents-goals view of function in which any intentional use of an object can be its function. On this view, younger children might be better prepared to solve problems requiring the generation of atypical functions. In terms of the informationprocessing approach to insight problems outlined earlier (Ohlsson, 1984), we explore the possibility that younger children's initial representation of the problem differs from that of older children. A more fluid notion of object function will reduce the restructuring requirement of the problem for the younger child. The older child, by contrast, will be required to restructure the problem so as to recognize an object as having the potential to fulfill an atypical function.

The experiment reported here assesses the performance of three age groups of children on a task analogous to Duncker's (1945) candle problem. In the new task, dubbed the box task, children were required to use an object (a box) for a purpose other than its conventional function (as a step to reach a high shelf, rather than as a container). It was predicted that when the conventional function was demonstrated (preutilization condition), younger children (here, 5-year-olds, as in German \& Johnson, 1997) would outperform older children on account of their more fluid notions about function. Moreover, only older children were anticipated to show functional fixedness, as marked by improved performance under conditions in which the object's proper function was not demonstrated (no-preutilization condition).

\section{METHOD}

\section{Design and Subjects}

The design was a 2 (condition: preutilization vs. no preutilization) $\times 3$ (age: 5-vs. 6-vs. 7-year-old) factorial design, with 60 children as subjects. Thirty children were randomly assigned to the preutilization condition: ten 5 -year-olds ( 4 boys, 6 girls; mean age 5 years 2 months, range 5-0 to 5-4), ten 6-year-olds ( 3 boys, 7 girls; mean age 6-0, range $5-10$ to $6-2$ ), and ten 7 -year-olds ( 4 boys, 6 girls; mean age $7-0$, range $6-10$ to $7-1$ ). The remaining 30 children were assigned to the no-preutilization condition: ten 5-year-olds ( 5 boys, 
5 girls; mean age 5-0, range 4-11 to 5-1), ten 6-year-olds (6 boys, 4 girls; mean age 5-11, range 5-10 to 6-2), and ten 7-year-olds ( 6 boys, 4 girls; mean age 6-11, range $6-10$ to $7-0$ ).

\section{Procedure}

The children were presented with a problem to solve in a quiet area of their classroom. They were shown a wooden box (measuring $38 \mathrm{~cm}$ wide $\times 25 \mathrm{~cm}$ deep $\times 58 \mathrm{~cm}$ high) with the front side and the top cut away, which was described as a room belonging to Bobo the Bear. On the "back" wall of the room was a shelf $(18 \mathrm{~cm}$ long) $30 \mathrm{~cm}$ from the floor, on which there was a toy (a model lion). The children were introduced to Bobo, a bear $10 \mathrm{~cm}$ high, and were told that Bobo wants to reach down his toy from the shelf but that he cannot reach the toy because he is short and cannot jump because he only has short legs. The children were told that Bobo has some things and were invited to show the experimenter how Bobo might use his things to get his toy (e.g., while the objects on the table were indicated with a gesture, the children were told: "Bobo has all these things; can you help him reach his toy, using any of these things?"). The objects were four building blocks ( $4 \mathrm{~cm}$ a side), a pencil, a ball $(9 \mathrm{~cm}$ in diameter), a small flat magnet in the shape of a bear, an eraser, a small toy car, a coin, and finally a wooden box $13.5 \mathrm{~cm}$ long $\times 13.5 \mathrm{~cm}$ wide $\times 12 \mathrm{~cm}$ high. In the preutilization condition, the other objects were all placed in the box, on the front edge of the room, at the start of the problem. In the no-preutilization condition, the objects were instead placed next to the box.

The building bricks could be stacked to make a tower $18 \mathrm{~cm}$ high, which combined with Bobo's height, would not allow the bear to reach the shelf. If the box was overturned and used as a support and a tower of bricks was built on top, Bobo could comfortably reach the shelf. The children's attempted solutions were scored as to whether the box was used, and the time elapsed before such a solution was measured. No specific hints were given, but if the children offered a solution by stopping their attempts and seeking approval from the experimenter without having so far used the box, the experimenter showed them that Bobo could not reach the toy and prompted them for another solution (e.g., the experimenter indicated the box and the remaining objects, and the children were told: "Is there anything else Bobo could use to get to his toy?"). We could thus be reasonably sure that all the children's attention was drawn to the box as a possible object for solution at some point in the procedure.

The children's attempted solutions were recorded on video for later analysis.

\section{RESULTS}

The subjects were scored according to whether or not they made use of the box in their solution to the problem, and the time elapsed before the box solution was offered (in seconds) was also recorded. A subset of the children's solutions was scored by a second rater. There were no disagreements as to whether or not a subject offered a box response. The longest time any child ever took in offering a box solution was $180 \mathrm{sec}$. Children who had not offered a box solution before this length of time had elapsed were deemed to have not offered such a solution. The number of children in each condition, at each age group, offering a box solution appears in Table 1 .

As can be seen from Table 1, a greater proportion of children offered a box solution in the no-preutilization condition than did so in the preutilization condition. However, in the 5-and 6-year-old groups, this difference was small. Only among the oldest children (7-year-olds) did the difference reach significance (Fisher's exact test, $p=.04$ ).

The mean times to solution in each condition, at each age group, for those children who offered a box solution also appear in Table 1 and can be seen plotted in the graph shown in Figure 1.

First, the predicted age trends were assessed. In the preutilization condition, solution times tended to increase with age (Jonckheere's trend test, $J=70, p<.005$ ). Younger children then, as was predicted, outperformed their older counterparts in generating the required alternative function in the face of the current conventional function. In the no-preutilization condition, the opposite trend was apparent, with solution times decreasing with age (Jonckheere's trend test, $J=145.5, J^{*}=2.06, p=$ $.0197)$. When the conventional function is not demonstrated, therefore, performance improves with age. ${ }^{2}$

The effect of condition at each age group was assessed with Mann-Whitney $U$ tests. These revealed faster times to solution in the no-preutilization condition than in the preutilization condition among 6-year-olds $(U=2, p<$ .005 ) and 7-year-olds $(U=1, p<.01)$, but no such difference at age $5(U=21, p=$ n.s. $)$. These results demonstrate that, as was predicted, older children show a deficit only under conditions of preutilization.

\section{DISCUSSION}

The results of this experiment are consistent with the notion of functional fixedness introduced by Duncker (1945). Older children, like the adults who were set Duncker's original candle problem (Adamson, 1952), appear to be hindered by their knowledge of an object's conventional function when that object must be used to serve an alternative goal in order to solve a problem and when the usual function has been demonstrated beforehand. When

Table 1

Percentage of Children Offering Box Solution and Mean Time to Solution (in Seconds; With Standard Deviations) at Each Age According to Condition

\begin{tabular}{|c|c|c|c|c|c|c|}
\hline \multirow[b]{3}{*}{ Age Group } & \multicolumn{6}{|c|}{ Condition } \\
\hline & \multicolumn{3}{|c|}{ Preutilization } & \multicolumn{3}{|c|}{ No Preutilization } \\
\hline & Percent Solving & Solution Time & $S D$ & Percent Solving & Solution Time & $S D$ \\
\hline 5-year-olds & 60 & 44.5 & 11.1 & 80 & 55.8 & 31.7 \\
\hline 6-year-olds & 60 & 113.8 & 32.2 & 90 & 50.7 & 16.4 \\
\hline 7-vear-olds & 40 & 115.3 & 61.0 & $89^{*}$ & 28.9 & 11.6 \\
\hline
\end{tabular}

Note $-N=10$ per condition. *Eight solutions $/ 9$ children: The data from 1 subject were excluded owing to experimenter error. 


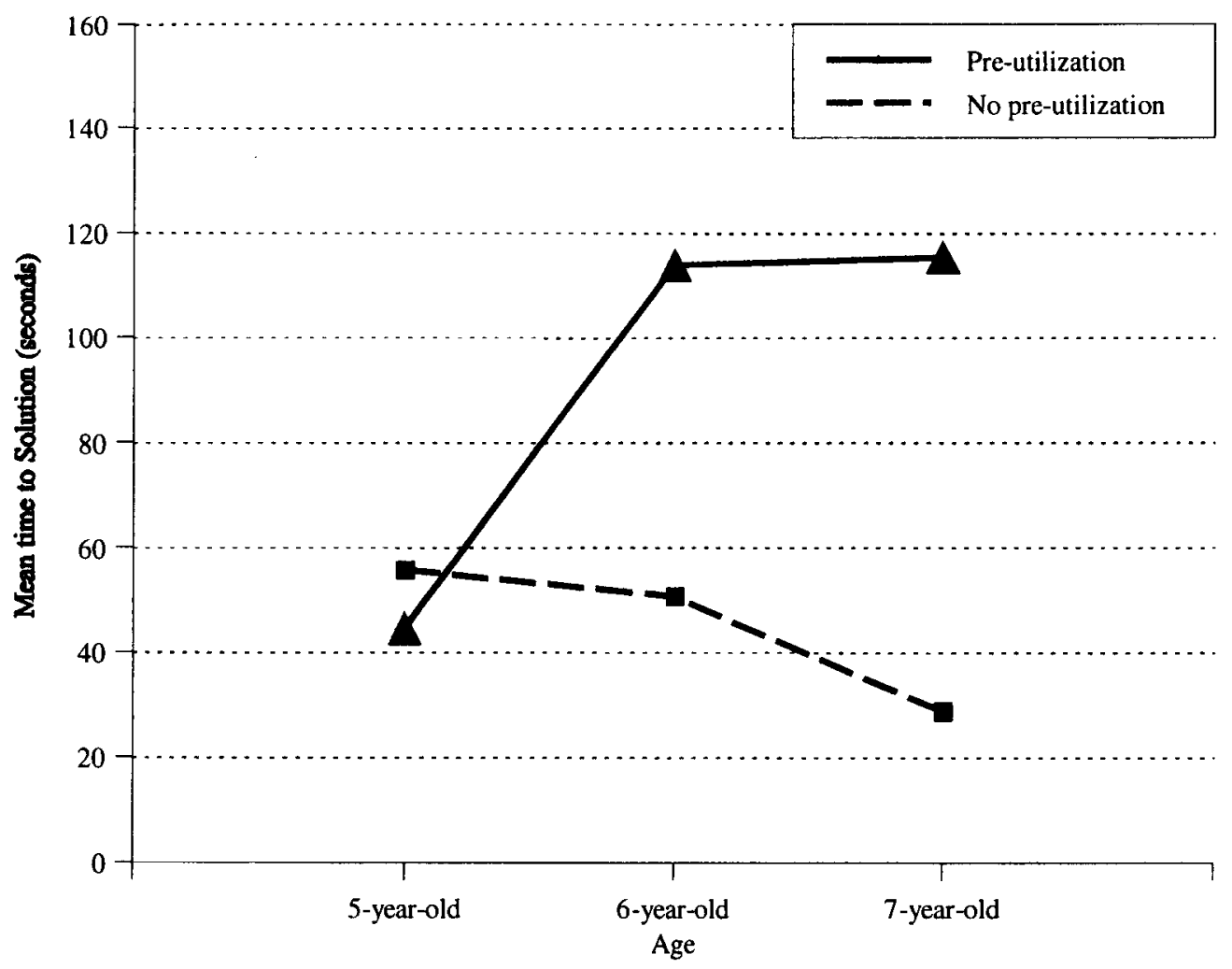

Figure 1. Graph showing mean time to solution (in seconds) as a function of age and condition.

the conventional function is not demonstrated, the pattern of performance across age matches what might be regarded as standard: Children's performance improves with increasing age. However, younger children do not seem to suffer from functional fixedness. First, 5-year-old children were quicker to solve the problem in the experimental preutilization condition than were children some 2 years older. Second, there was no advantage for the 5 -year-old group in the no-preutilization condition; children were as quick to solve when the object's conventional function was demonstrated as when it was not. ${ }^{3}$

The pattern of results in the preutilization condition runs counter to the general view on problem-solving abilities and increasing mental age, which would expect older children to fare better than their younger peers in problemsolving tasks. In addition, there was no support for the specific proposal that functional fixedness might be even more pronounced in younger children on account of the box task's requiring the inhibition of a salient current piece of world knowledge.

An obvious concern, given the counterintuitive nature of these results and the relatively small sample size, is whether the finding is reliable. Further work in our laboratory (Defeyter \& German, 2000) has twice replicated and extended these findings in a much larger sample. In these replications, we focused on the performance of 5and 7-year-old groups of children given the same box task, under the same two conditions (total $N=100$ ). It was found that whereas the younger children again showed no evidence of functional fixedness $(64 \%$ offered box solutions under conditions of preutilization, $65 \%$ under conditions of no preutilization), the older children showed a marked decline in performance when the function was demonstrated ( $18 \%)$, as compared with when it was not $(89 \%)$. Moreover, younger children significantly outperformed their older peers in the preutilization condition, whereas the reverse effect was evident in the no-preutilization condition, confirming the present findings. A further concern was also addressed in this replication. It was made clear to all the children that the box was an eligible item to use in the solution by specifically drawing their attention to it (by pointing it out and labeling it) in the presentation of the problem (i.e., "Bobo has this box and all this stuff... can you help him use any of these things ..."). This procedure was carried out in order to supplement the measures taken in the present study (see the Method section) to ensure that all children were as clear as possible on the game rules and the eligibility of the box solution. Overall then, the results of the study reported here appear to be robust.

Under the information-processing approaches outlined in the introduction (Keane, 1989; Ohlsson, 1984), impasses in problem solving were assumed to be the result of inappropriate initial encoding of the problem, and problem solution was assumed to be facilitated by restructuring this initial encoding. Within this framework, we can identify two possible reasons for younger children's superior performance on the box task: Either their 
initial encoding of the problem does not lead to impasse, or they are better at restructuring than their older peers. We will focus on the first of these two possibilities. ${ }^{4}$

How might younger children's initial encoding of the problem be different from that of older children? The proposal favored here is that younger children's conception of function is more fluid than that of older children and adults. On this view, younger children have a wider criterion for what can count as an object's function; they view object function in terms of any goals of its users, rather than in terms of one specific originally intended function (German \& Johnson, 1997). This will provide a degree of flexibility when they are faced with reasoning about the possible functions of an object, and the efficient generation of an atypical function will not be blocked. Older children, by contrast, are assumed to view object functions more rigidly. Demonstration of the containment function fixes that function in their initial representation of the problem, and this initial representation must be restructured before a solution can be reached.

An alternative possibility is that younger children's initial problem representation is different not because their intuitions of function are fluid, but rather because they may be operating with an impoverished notion of function. That is, children may not even appreciate that boxes are typically used as containers and, therefore, fail to represent the initial containment function in the first place. This possibility might be considered compatible with the inhibition hypothesis outlined in the introduction; if younger children do not represent the initial containment function, there is no prepotent state of affairs that needs to be set aside and no consequent inhibitory demands.

Although the characterization of these positions seem similar, there is evidence suggesting that the former position may more likely be the correct one. First, children begin imitating the conventional functions of everyday objects (e.g., spoons, brushes, keys, etc.) from the end of the 1st year of life (Abravanel \& Gingold, 1985; McDonough \& Mandler, 1998). Second, Gauvain and Greene (1994) have shown that as well as being able to give accurate demonstrations of object functions from age 2, by age 4 children are also competent at giving verbal descriptions of the appearance and function of everyday objects (again, objects such as brushes, pencils, etc.). We therefore consider it unlikely that in the present study, the 5 -year-old children were unable to appreciate the box-ascontainer demonstration.

None of the above studies, however, provides direct evidence that children understand boxes to be typically used for containment, and therefore it remains possible that the results obtained in this study reflect impoverished specific functional knowledge among younger children, rather than flexible intuitions about function in general. It may be possible to test these hypotheses directly. If younger children are rendered immune to functional fixedness as a result of different knowledge about specific real objects, no such effect should be observed if a task were to involve novel objects where the functions are taught directly to all children. However, if immunity is created by young children's flexibility in intuitions about function in general, we should expect them to succeed where older children are hindered, in a task that requires setting aside the newly taught function of a novel object and using that object for an alternative purpose.

\section{REFERENCES}

Abravanel, E., \& Gingold, H. (1985). Learning via observation during the second year of life. Developmental Psychology, 21, 614-623.

Adamson, R. E. (1952). Functional fixedness as related to problem solving: A repetition of three experiments. Journal of Experimental Psychology, 44, 288-293

Campione, J., Brown, A., \& Ferrera, R. (1982). Mental retardation and intelligence. In R. J. Sternberg (Ed.), Handbook of human intelligence (pp. 392-490). Cambridge: Cambridge University Press.

CASE, R. (1985). Intellectual development: Birth to adulthood. Orlando, FL: Academic Press.

Defeyter, M. A. \& German, T. P. (2000, September). Immunity to fractional fixedness in young children: Flexibte or impoverished undersianding of object function? Poster presented at the BPS Cognitive Section Conference, University of Essex.

Dominowski, R. L. (1981). Comment on "An examination of the alleged role of 'fixation' in the solution of several "insight' problems" by Weisberg and Alba. Journal of Experimental Psychology: General, 110, 199-203.

Dominowski, R. L., \& DALloB, P. (1995). Insight and problem solving. In R. J. Sternberg \& J. E. Davidson (Eds.), The nature of insight (pp. 33-62). Cambridge, MA: MIT Press.

DUNCKER, K. (1945). On problem solving. Psychological Monographs, 58, 5 (Whole No. 270).

GauvalN, M., \& GREenE, J. K. (1994). What do young children know about objects? Cognitive Development, 9, $311-329$.

German, T. P., \& Johnson, S. A. (1996, August). Children's knowledge of artifacts: Origins of the "design stance." Poster presented at the XXVI International Congress of Psychology, Montreal. [Abstract: International Journal of Psychology, 31, 342]

German, T. P., \& JohnSON, S. A. (1997, April). Agents, goals and origins: Children's understanding of artifact function. Paper presented at the biennial meeting of the Society for Research in Child Development, Washington, DC.

GopNik, A., \& Meltzoff, A. N. (1997). Words, thoughts and theories. Cambridge, MA: MIT Press.

Hughes, C. (1998). Executive function in preschoolers: Links with theory of mind and verbal ability. British Journal of Developmental Psychology, 16, 233-253.

KEANE, M. T. (1989). Modelling problem solving in Gestalt "insight" problems. Irish Journal of Psychology, 10, 201-215.

KELEMEN, D. A. (1999). The scope of teleological thinking in preschool children. Cognition, 70, 241-272.

LESLIE, A. M., \& PolizzI, P. (1998). Inhibitory processing in the false belief task: Two conjectures. Developmental Science, 1, 247-253.

MaIer, N. R. F. (1970). Problem solving and creativity in individuals and groups. Belmont, CA: Brooks/Cole.

Marcus, G. F., Pinker, S., Ullman, M. H., Rosen, T. J., \& Xu, F. (1992). Over-regularization in language acquisition (Monographs of the Society for Research in Child Development, Vol. 57, No. 4). Chicago: Society for Research in Child Development.

MCDONOUGH, L., \& MANDLER, J. (1998). Inductive generalization in 9. and 11-month-olds. Developmental Science, 1, 227-232.

Morton, J., \& Johnson, M. H. (1991). CONSPEC and CONLERN: A two-process theory of infant face recognition. Psychological Review, 98, 164-181.

OHLSSON, S. (1984). Restructuring revisited: II. An information processing theory of restructuring and insight. Scandinavian Journal of Psychology, 25, 117-129.

PIAGET, J. (1954). The construction of reality in the child. New York Basic Books. (Original work published 1937)

Russell, J., Jarrold, C., \& Potel, D. (1994). What makes strategic deception difficult for children-the deception or the strategy? British Journal of Developmental Psychology, 12, 301-314. 
Siegler, R. (1996). Emerging minds: The process of change in children's thinking. New York: Oxford University Press.

WeISBERG, R. W., \& ALBA. J. W. (1981a). An examination of the alleged role of "fixation" in the solution of several "insight" problems. Journal of Experimental Psychology: General, 110, 169-192.

WEIsBerG, R. W., \& Alba, J. W. (1981b). Gestalt theory, insight and past experience: Reply to Dominowski. Journal of Experimental Psychology: General, 110, 193-198.

Wimmer, H., \& Perner, J. (1983). Beliefs about beliefs: Representation and constraining function of wrong beliefs in children's understanding of deception. Cognition, 53, 45-57.

\section{NOTES}

1. It should be noted that notions such as fixation and insight are not unproblematic in the problem-solving literature (e.g., Weisberg \& Alba, 1981 a, 1981b; however, see also Dominowski, 1981).
2. These analyses were carried out on solution latencies for solvers only. Including nonsolvers and scoring them at $180 \mathrm{sec}$ does not substantially change the picture. The trend in the preutilization condition remains significant $\left(J=201, J^{*}=1.94, p=.0262\right)$, whereas the trend in the no-preutilization condition is marginally significant $\left(J=174, J^{*}=\right.$ $1.52, p=.0643$ )

3. In fact, what difference there was with this age group was in the opposite direction, although not significant.

4. Where discussed, restructuring is assumed to involve the application of complicated metacognitive processes (or metaheuristics; see Ohlsson, 1984). Such processes are known to develop in the early school years and are extremely unlikely to be superior in younger children (see, e.g., Campione, Brown, \& Ferrera, 1982, for a review).

(Manuscript received February 18, 1999 revision accepted for publication November $2,1999$. 